\title{
41. DIAGNOSIS OF EMPLACEMENT MODE OF BASALT IN HOLE 319A AND SITE 321
}

\author{
Brooks B. Ellwood and Norman D. Watkins, Graduate School of Oceanography, \\ University of Rhode Island, Kingston, Rhode Island
}

\begin{abstract}
Measurements of the anisotropy of magnetic susceptibility (AMS) in basalt cores between 125 and 130 meters depth at Site 321 reveal a consistently near-horizontal direction of minimum susceptibility, with the directions of intermediate and maximum susceptibility confined to a vertical plane. Together with a low stability of remanent magnetism, this is indicative of an intrusive origin. In contrast, basalt between 90 and 150 meters depth in Hole 319A possesses highly variable AMS directions and remanent magnetism stability, showing the presence of several different bodies of probably mixed emplacement mode.
\end{abstract}

\section{INTRODUCTION}

Magnetic susceptibility $(K)$ when measured in low alternating magnetic fields $(\bar{H})$ can be represented by the function:

$$
\overrightarrow{J i}=K \mathrm{ij} \overrightarrow{H j}
$$

where $\overrightarrow{J i}$ is the intensity of induced magnetization.

Anisotropy of magnetic susceptibility (AMS) data are conventionally expressed as a triaxial ellipsoid whose major, intermediate, and minor axis represent the corresponding susceptibility directions and magnitudes, identified as $K \mathrm{a}, K \mathrm{~b}$, and $K \mathrm{c}$, respectively. In a basaltic rock specimen, the orientation of the ellipsoid represents the net preferred alignment of magnetic grains. It is probable that net preferred alignment can be increased in basalts by flow during emplacement; initial solidification is a stress field; or mild postemplacement metamorphism involving stress. Thus AMS is possibly relevant to distinguishing between igneous emplacement modes (Ellwood and Watkins, 1973).

There has been some difficulty in determining the mode of emplacement of basaltic materials recovered by DSDP when no observations, such as baked sediment contacts, are recovered. In this communication, results of the measurement of the AMS of basaltic cores from Leg 34, Hole 319A and Site 321 are presented.

\section{METHODS}

The remanent magnetism of all specimens was measured using a Digico spinner magnetometer, and unstable components were examined using alternating magnetic fields. The AMS of all samples was then measured with a low-field torque meter, similar to that described by Stone (1963). The torque meter was calibrated with a seamless machined copper ring (Noltimier, 1964). Maximum sensitivity of the instrument is $4.0 \times 10^{-9}$ cgs volume susceptibility difference per millimeter scale division. The total volume susceptibility difference per millimeter scale division. The total volume susceptibility $(\chi)$ was measured on a $300-\mathrm{Hz}$ susceptibility bridge (Collinson et al., 1963) and calibrated with several samples previously measured on a susceptibility bridge, designed and built by Dr. J. Balsely at the U.S. Geological Survey in Washington, D.C., and by use of standard salts.

\section{RESULTS}

Table 1 presents the AMS results for Hole 319A and Site 321. Figures 1 and 2 are plots versus depth in the holes for the total susceptibility $(\chi)$, percent anisotrophy (\%AN), and a measure of the stability of remanent magnetization given as $J_{100}$ and $J_{0}$ are the intensity of magnetization $(J)$ after demagnetization at 100 oersteds peak field and the untreated natural remanent magnetism, respectively.

\section{DISCUSSION}

Susceptibility, Percent Anisotropy, and Stability of Remanent Magnetism

Figures 1 and 2 show the relationships between the three magnetic parameters $\chi, \% \mathrm{AN}$, and $J_{100} / J_{0}$. A statistical analysis of the data in Hole 319A (Figure 1) shows that $\chi$ is inversely proportional to magnetic stability $\left(J_{100} / J_{0}\right)$ at the $99.9 \%$ significance level. This is consistent with magnetic stability being preferentially associated with the finer sized magnetic grains, which is to be expected (Watkins and Haggerty, 1967). The data in Figure 1 could, therefore, reflect major fluctuations in magnetic grain size in Hole 319A, requiring the presence of several separate bodies.

The data for Site 321 (Figure 2) are less variable. Such relative consistency might be expected for a single unit. The lower $J_{100} / J_{0}$ observed would be consistent with larger magnetic grain sizes.

\section{Directions of Susceptibility Anisotropy}

AMS directional data from subaerial basalt samples with known geographic orientations are conventionally presented graphically on stereographic or equal area projections. Since even intra-unit orientations are unknown in most DSDP materials, such projections become meaningless unless some method of relative or 
TABLE 1

AMS Results for Hole 319A and Site 321

\begin{tabular}{|c|c|c|c|c|c|c|c|c|c|c|c|c|}
\hline $\begin{array}{l}\text { Sample } \\
\text { (Interval } \\
\text { in } \mathrm{cm} \text { ) }\end{array}$ & $\begin{array}{l}\text { Depth } \\
\text { (m) }\end{array}$ & $x \times 10^{-4}$ & $K a \times 10^{-4}$ & $K \mathrm{~b} \times 10^{-4}$ & $K c \times 10^{-4}$ & $D \max$ & $\operatorname{Imax}$ & Dint & Iint & Dmin & Imin & $\%$ AN \\
\hline $319 \mathrm{~A}-1-1,42$ & 98.4 & 8.8 & 9.03 & 8.85 & 8.74 & 84.1 & -3.7 & 347.3 & -61.1 & 176.1 & -28.6 & 3.2 \\
\hline $319 A-1-1,86$ & 98.9 & 1.8 & 1.84 & 1.83 & 1.82 & 96.2 & -30.3 & 196.2 & -16.6 & 311.0 & -54.6 & 1.0 \\
\hline $319 \mathrm{~A}-1-1,117$ & 99.1 & 1.8 & 1.80 & 1.78 & 1.77 & 264.5 & -5.6 & 158.8 & -69.9 & 356.4 & -19.2 & 1.9 \\
\hline $319 \mathrm{~A}-1-1,130$ & 99.3 & 1.6 & 1.65 & 1.64 & 1.63 & 135.0 & -18.8 & 30.5 & -36.4 & 246.9 & -47.5 & 1.3 \\
\hline $319 A-2-1,13$ & 107.6 & 1.9 & 1.94 & 1.93 & 1.93 & 57.4 & -6.9 & 161.4 & -63.3 & 324.1 & -25.6 & 0.5 \\
\hline $319 \mathrm{~A}-2-1,102$ & 108.5 & 1.7 & 1.75 & 1.73 & 1.71 & 96.0 & -1.1 & 188.5 & -65.2 & 5.5 & -24.8 & 2.3 \\
\hline $319 \mathrm{~A}-2-2,27$ & 109.3 & 1.3 & 1.27 & 1.25 & 1.23 & 81.9 & -16.2 & 216.3 & -67.5 & 347.4 & -15.2 & 3.1 \\
\hline $319 \mathrm{~A}-2-2,115$ & 110.1 & 5.3 & 5.27 & 5.26 & 5.23 & 310.1 & -20.5 & 148.2 & -68.6 & 42.4 & -6.1 & 0.9 \\
\hline $319 \mathrm{~A}-2-3,40$ & 110.9 & 1.8 & 1.85 & 1.84 & 1.82 & 121.8 & -47.0 & 221.2 & -8.7 & 319.0 & -41.7 & 1.8 \\
\hline $319 \mathrm{~A}-3-1,50$ & 117.5 & 13.0 & 12.89 & 12.85 & 12.70 & 189.3 & -36.3 & 2.3 & -53.5 & 96.8 & -3.4 & 1.5 \\
\hline $319 A-3-1,65$ & 117.7 & 17.0 & 16.67 & 16.38 & 16.18 & 223.6 & -72.7 & 74.1 & -15.0 & 341.9 & -8.4 & 3.0 \\
\hline $319 \mathrm{~A}-3-1,89$ & 117.9 & 31.0 & 31.00 & 30.60 & 30.14 & 167.7 & -85.3 & 354.6 & -4.6 & 264.6 & -0.6 & 2.9 \\
\hline $319 A-3-2,68$ & 119.2 & 3.4 & 3.45 & 3.40 & 3.30 & 224.1 & -12.1 & 103.2 & -67.3 & 318.3 & -18.9 & 4.3 \\
\hline $319 \mathrm{~A}-3-2,70$ & 119.3 & 1.4 & 1.43 & 1.37 & 1.32 & 243.2 & -10.1 & 78.6 & -79.5 & 333.7 & -2.7 & 7.9 \\
\hline $319 A-3-3,14$ & 120.1 & 4.8 & 4.89 & 4.85 & 4.82 & 124.9 & -19.7 & 12.8 & -46.5 & 230.5 & -37.0 & 1.3 \\
\hline $319 A-3-3,64$ & 120.6 & 16.0 & 1.61 & 1.60 & 1.58 & 180.0 & -69.5 & 0.0 & -20.5 & 270.0 & 0.0 & 1.6 \\
\hline $319 A-3-3,76$ & 120.7 & 23.0 & 23.47 & 23.16 & 23.10 & 278.0 & -77.5 & 70.3 & -11.1 & 161.5 & -5.7 & 1.6 \\
\hline $319 \mathrm{~A}-3-3,110$ & 121.1 & 34.0 & 34.16 & 33.86 & 32.85 & 354.0 & -82.6 & 163.5 & -7.3 & 253.6 & -1.3 & 3.9 \\
\hline $319 A-3-4,37$ & 121.9 & 33.0 & 34.41 & 34.22 & 33.54 & 349.4 & -9.2 & 157.6 & -80.6 & 259.1 & -1.9 & 2.6 \\
\hline $319 A-3-4,53$ & 122.0 & 29.0 & 30.06 & 29.03 & 28.63 & 298.9 & 0.0 & 208.9 & -3.9 & 29.4 & -86.1 & 4.9 \\
\hline $319 A-3-5,61$ & 123.6 & 27.0 & 27.07 & 26.86 & 26.47 & 214.2 & -70.9 & 317.2 & -4.5 & 48.7 & -18.5 & 1.6 \\
\hline $319 A-3-5,72$ & 123.7 & 29.0 & 29.03 & 28.80 & 28.59 & 97.2 & -76.7 & 347.6 & -4.5 & 256.6 & -12.5 & 2.1 \\
\hline $319 A-3-5,95$ & 123.9 & 1.6 & 1.67 & 1.65 & 1.65 & 246.0 & -4.5 & 54.5 & -18.1 & 349.5 & -71.3 & 0.9 \\
\hline $319 \mathrm{~A}-3-5,104$ & 124.0 & 1.7 & 1.77 & 1.75 & 1.73 & 210.1 & -16.0 & 117.5 & -8.9 & 359.5 & -71.6 & 2.3 \\
\hline $319 A-3-5,113$ & 124.2 & 2.4 & 2.39 & 2.37 & 2.36 & 94.4 & -0.9 & 185.4 & -47.9 & 3.6 & -42.1 & 1.1 \\
\hline $319 A-3-5,135$ & 124.4 & 2.7 & 2.71 & 2.70 & 2.68 & 108.7 & -18.7 & 16.0 & -7.7 & 264.6 & -69.7 & 1.3 \\
\hline $319 A-3-6,82$ & 125.3 & 1.4 & 1.45 & 1.43 & 1.42 & 265.5 & -29.1 & 140.9 & -45.5 & 14.4 & -30.3 & 2.0 \\
\hline $319 \mathrm{~A}-4-1,97$ & 127.5 & 29.0 & 28.96 & 28.49 & 27.89 & 14.9 & -75.6 & 198.8 & -14.3 & 108.6 & -0.9 & 3.8 \\
\hline 319A-5-1, 112 & 129.6 & 8.1 & 8.19 & 8.08 & 8.04 & 313.5 & -28.8 & 47.4 & -7.1 & 149.9 & -60.2 & 1.9 \\
\hline $319 A-5-1,145$ & 130.0 & 2.6 & 2.65 & 2.63 & 2.61 & 75.0 & -1.3 & 167.7 & -64.5 & 344.4 & -25.4 & 1.5 \\
\hline 319A-6-1, 78 & 138.7 & 1.4 & 1.45 & 1.44 & 1.43 & 60.6 & -5.3 & 159.7 & -59.6 & 327.6 & -29.8 & 1.4 \\
\hline $319 \mathrm{~A}-6-1,116$ & 139.0 & 1.8 & 1.76 & 1.76 & 1.74 & 78.3 & -19.5 & 292.2 & -66.9 & 172.6 & -11.9 & 1.3 \\
\hline $319 \mathrm{~A}-7-1,58$ & 148.0 & 3.1 & 3.09 & 3.07 & 3.04 & 43.7 & -50.0 & 254.8 & -35.7 & 153.2 & -15.6 & 1.8 \\
\hline $321-14-1,52$ & 125.5 & 21.0 & 21.42 & 21.24 & 20.92 & 256.2 & -84.9 & 13.3 & -2.3 & 103.5 & -4.5 & 2.4 \\
\hline $321-14-1,55$ & 125.5 & 17.0 & 17.25 & 17.06 & 16.91 & 149.0 & -74.4 & 14.6 & -11.0 & 287.4 & -10.9 & 2.0 \\
\hline $321-14-1,88$ & 125.9 & 18.0 & 18.16 & 17.94 & 17.38 & 286.2 & -85.4 & 180.6 & -1.2 & 90.5 & -4.4 & 4.3 \\
\hline $321-14-2,49$ & 127.0 & 25.0 & 25.47 & 24.91 & 24.71 & 171.1 & -34.3 & 41.9 & -42.9 & 282.4 & -28.0 & 3.0 \\
\hline $321-14-2,94$ & 127.4 & 33.0 & 33.08 & 32.89 & 32.49 & 107.6 & -82.1 & 209.1 & -1.6 & 299.4 & -7.7 & 1.8 \\
\hline $321-14-3-1$ & 128.0 & 55.0 & 55.65 & 55.35 & 54.36 & 180.4 & -8.5 & 38.5 & -79.3 & 271.3 & -6.5 & 2.4 \\
\hline $321-14-3,4$ & 128.0 & 25.0 & 25.12 & 25.03 & 24.20 & 2.6 & -27.2 & 190.7 & -62.6 & 94.3 & -3.3 & 3.7 \\
\hline $321-14-3,97$ & 129.0 & 52.0 & 52.45 & 52.12 & 50.72 & 180.4 & -4.1 & 33.0 & -85.1 & 270.9 & -2.6 & 3.3 \\
\hline $321-14-4,12$ & 129.6 & 59.0 & 60.03 & 59.35 & 58.43 & 4.3 & -28.4 & 175.7 & -61.3 & 272.3 & -3.6 & 2.7 \\
\hline $321-14-4,42$ & 129.9 & 52.0 & 52.35 & 52.22 & 51.37 & 183.9 & -43.7 & 5.9 & -46.3 & 274.8 & -1.0 & 1.9 \\
\hline
\end{tabular}

NOTE: $\chi=$ volume susceptibility in cgs units; $K \mathrm{a}, K \mathrm{~b}, \mathrm{Kc}=$ susceptibility of (a) maximum, (b) intermediate, (c) minimum susceptibility magnitudes, respectively, in cgs units, corresponding directions given by $\mathrm{D}$ and I max., int., and min. where $\mathrm{D}=$ declination in degrees east of an arbitrary zero azimuth; $I=$ inclination in degrees with respect to the horizontal, negative above the horizon; \% $\mathrm{AN}=$ $(K a-K c) / K b \times 100$.

absolute reorientation can be employed. One such method is to determine the direction of stable magnetism for the hole, and, assuming that it is constant for the entire hole, use it to realign each specimen (Ellwood and Watkins, 1973). When the stability of remanent magnetism is very low, however, as we have independently determined to be the case for much (but not all) of the material in 319A and 321, this technique cannot be used. Another method has therefore been used to examine the relative orientations of the AMS results in these two holes. It has previously been shown (Ellwood and Watkins, 1973) that some intrusives can be identified by the presence of a well-grouped minimum or maximum susceptibility axis with the maximum and intermediate directions, or intermediate and minimum directions, being distributed in a plane normal to the well-grouped set of axes. Plots of the inclination versus depth in a hole for the maximum, intermediate, and minimum AMS inclinations will therefore yield at least one relatively consistent inclination.

Figures 3 and 4 illustrate the down-core variation of the inclination of the maximum (Imax), intermediate (lint), and minimum (Imin) axes in Hole 319A and Site 321. Figure 3a shows that the material from Site 321 has a consistently nearly flat minimum susceptibility inclination with a large scatter of both maximum and intermediate AMS inclinations within a single plane. In contrast, the Hole 319A materials show no such consistency in inclinations for the core (Figure 4a). Alternative displays of the data are in Figures $3 \mathrm{~b}$ and $4 \mathrm{~b}$, where histograms of Imax, Iint, and Imin occurrences are shown. At Site 321 (Figure 3a), the Imin is clearly nonrandom, while the Imax and Iint are random. Although exhibiting a tendency for lower Imin values, the data for Hole 319A (Figure 4b) are essentially random for all three axes. 


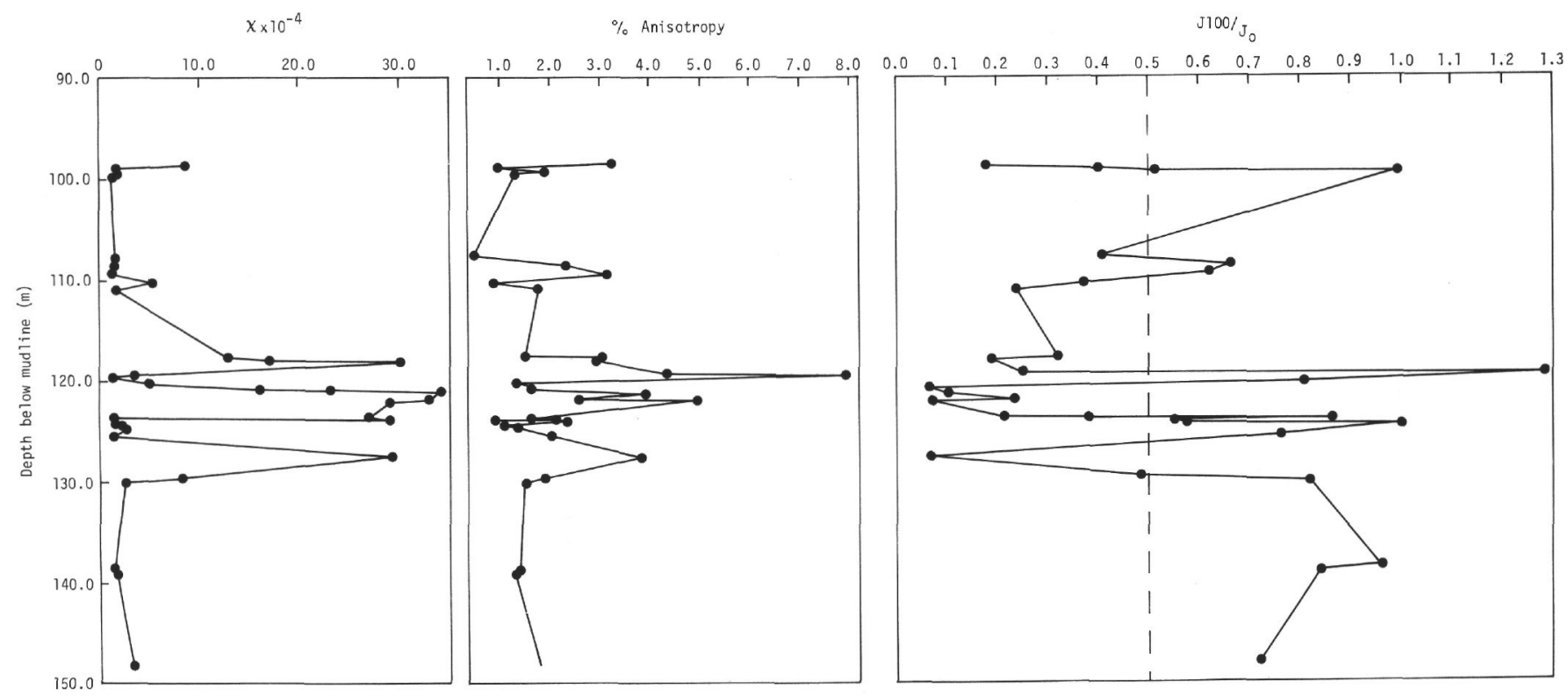

Figure 1. Magnetic properties as a function of depth in Hole $319 \mathrm{~A}$ below the mudline. $\chi=$ total volume susceptibility in cgs units; $J_{100} / J_{0}=$ ratio of remanent magnetism intensity after 100 oe peak field demagnetization to that of the untreated specimen (or natural remanent magnetism).

Hole 321

$$
x \times 10^{-3} \% \text { Anisotropy } \quad \mathrm{J} 100 / \mathrm{J}_{0}
$$

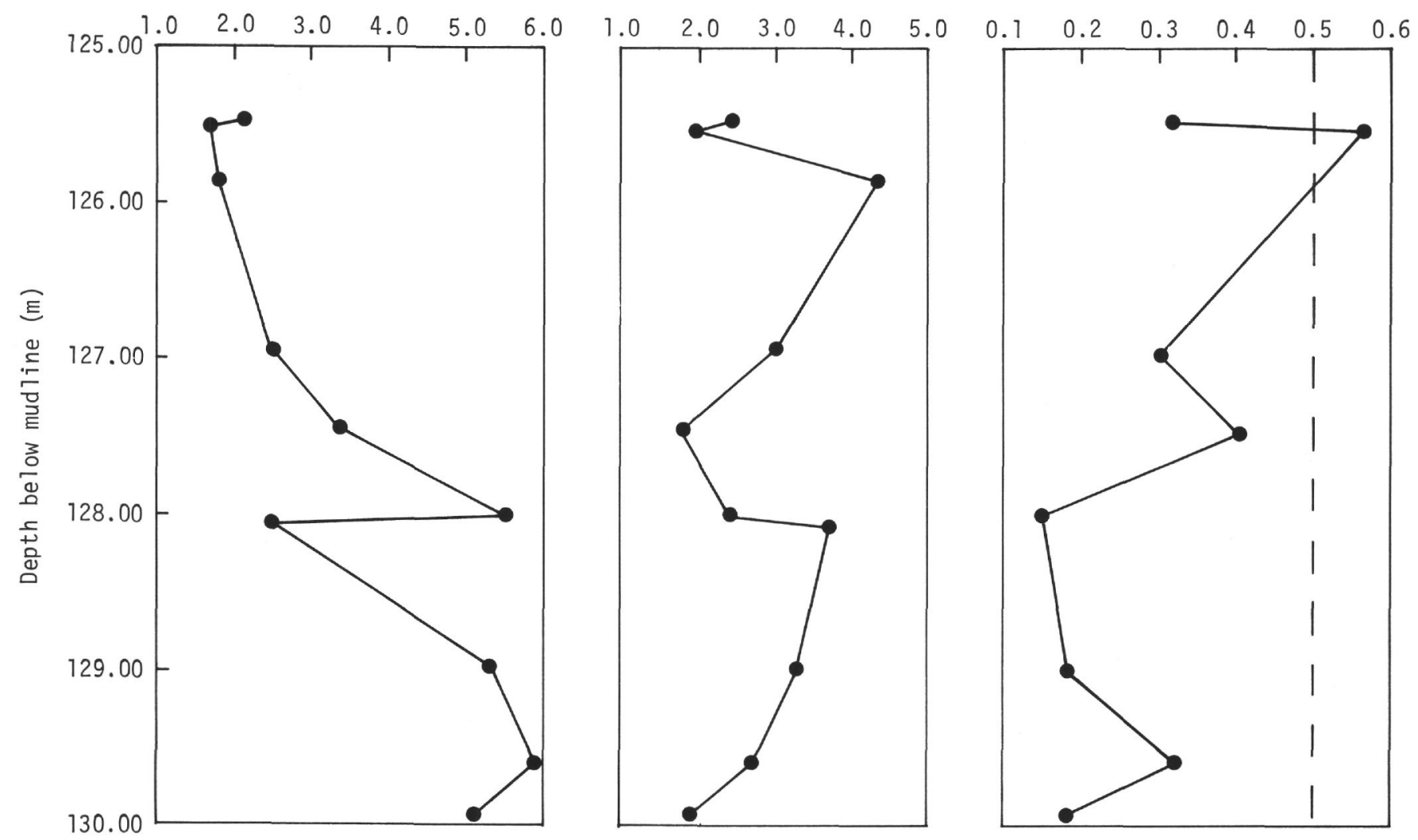

Figure 2. Magnetic results as a function of depth at Site 321 below the mudline. See Figure 1 for a definition of symbols. 

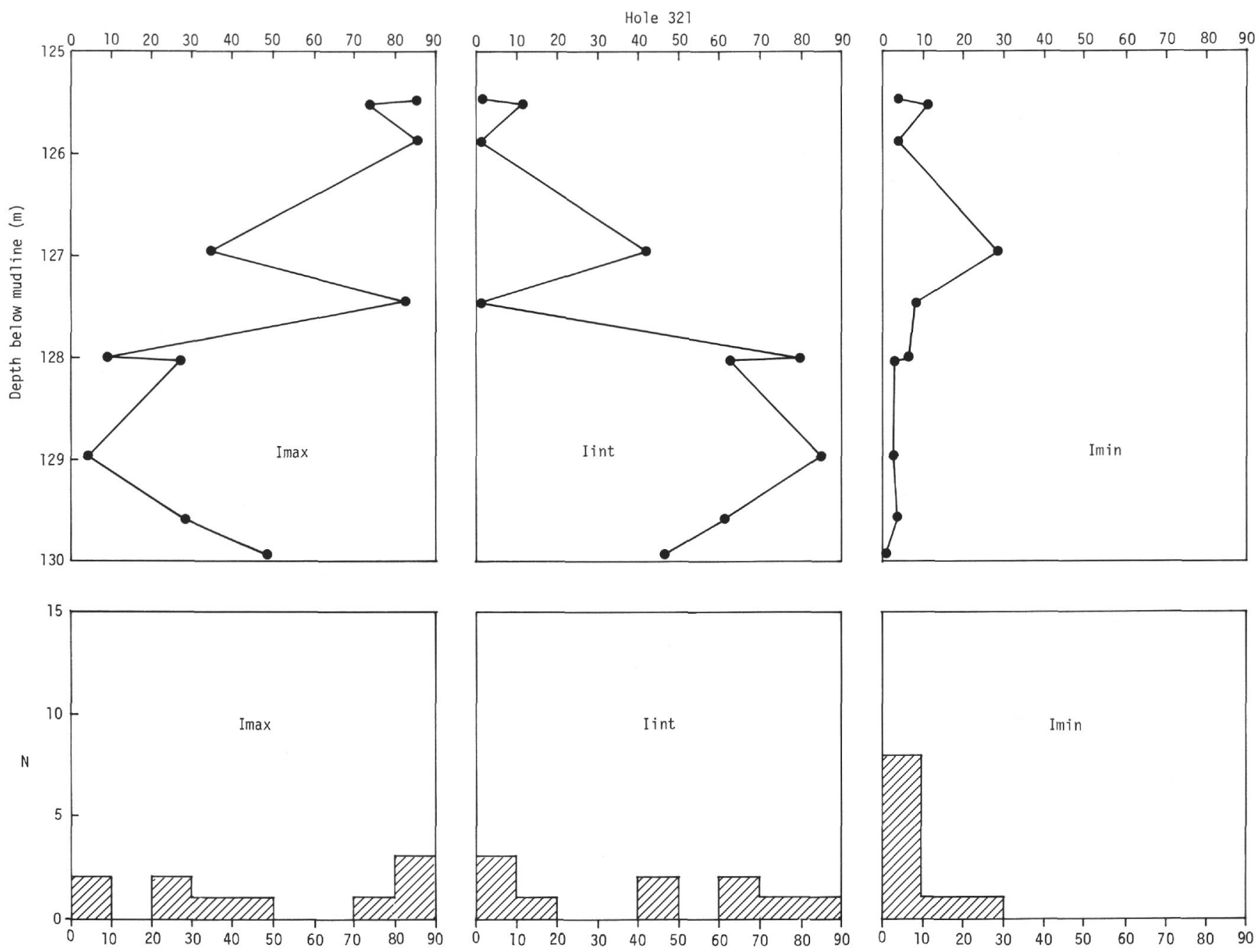

Figure 3. (a) AMS inclination as a function of depth at Site 321 below the mudline. Imax, Iint, Imin =inclination of maximum, intermediate, and minimum AMS directions in degrees above the horizontal. Note that the complimentary nature of Imax and Imin is an inherant property when two such parameters are confined (or nearly confined) to a single plane. (b) Corresponding histograms of Imax, Iint, and Imin AMS inclinations at Site 321. N= numbers of observations. Intervals are at $10^{\circ}$.

\section{CONCLUSIONS}

We believe that the materials measured from Site 321 are probably of intrusive origin, because they possess clearly preferred directions of AMS with the minimum direction being close to horizontal, and the intermediate and maximum axes being randomly distributed, but confined to a vertical or nearly vertical plane. This conclusion is supported by the low stability of remanent magnetism throughout the core, suggesting the presence of larger titanomagnetites which are most readily associated with slower cooling bodies. In contrast, our materials from Hole 319A span a much greater depth and yield data requiring the presence of several different bodies, as independently determined by the petrographic examinations described elsewhere in this report. We suspect, however, that the interval 107.5 to 130 meters depth may contain more than the three separate bodies indicated by petrographic studies: in particular, a possible discrete body is indicated by our data between
117 and 121 meters depth, and this was nowhere detected by the methods used during the shipboard examination, but neither was such a possibility excluded.

\section{REFERENCES}

Collinson, D.W., Stone, B.D., and Molyneux, L., 1963. A total and anisotropic magnetic susceptibility meter: J. Sci. Instrum., v. 40, p. 310-312.

Ellwood, B.B. and Watkins, N.D., 1973. Anisotropy of magnetic susceptibility and emplacement modes of submarine igneous rocks: Am. Geophys. Union Trans., v. 54, p. 95-96.

Noltimier, H.C., 1964. Calibration of a spinner magnetometer with a wire loop: J. Sci. Instrum., v. 41, p. 55.

Stone, D.B., 1963. Anisotropic magnetic susceptibility measurements on a phonolite and on a folded metamorphic rock: Geophys. J., v. 7, p. 375-390.

Watkins, N.D. and Haggerty, S.E., 1967. Primary oxidation variation and petrogenesis in a single lava: Contrib. Mineral. Petrol., v. 15, p. 251-271. 

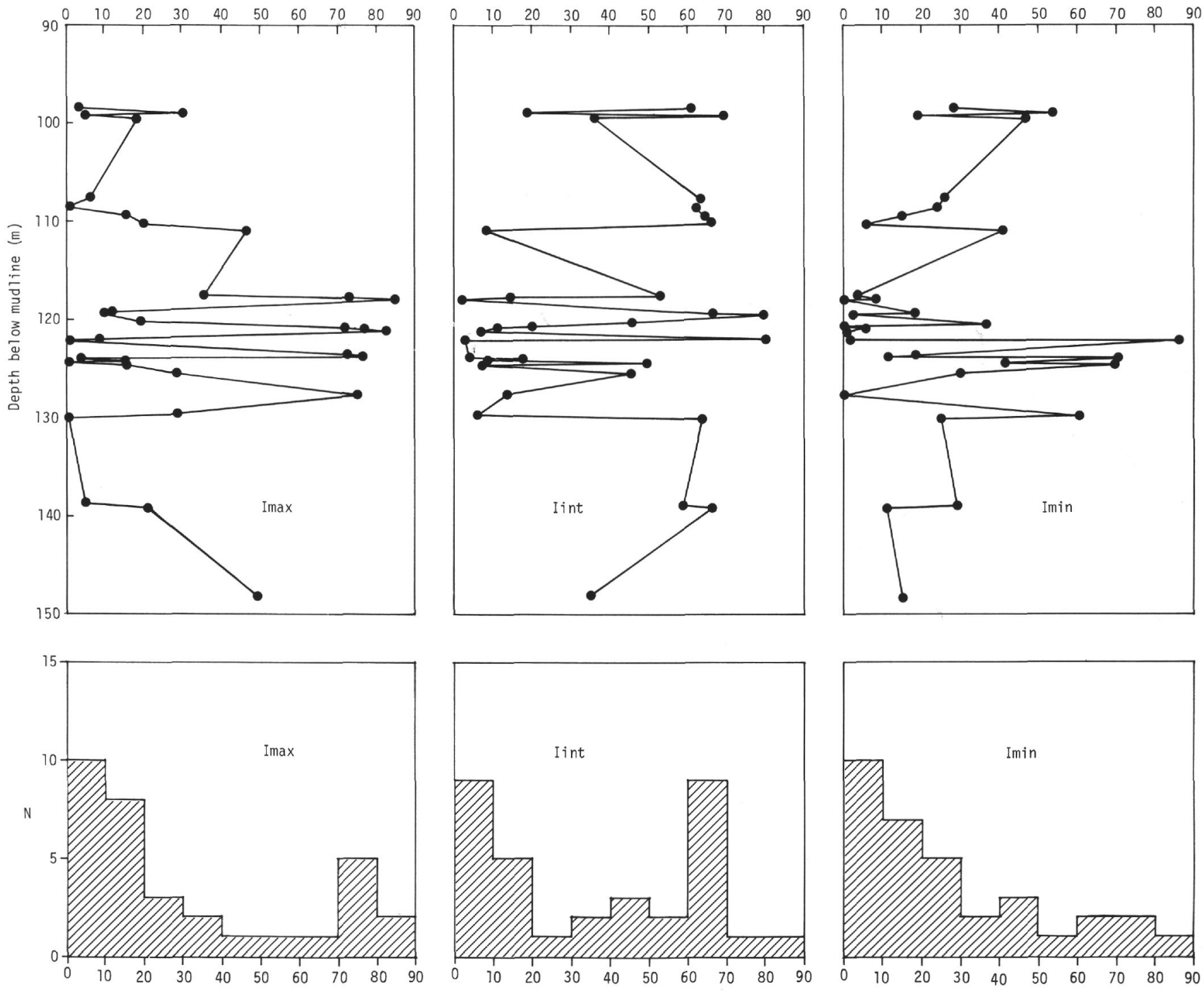

Figure 4. (a) AMS inclinations as a function of depth in Hole 319A below the mudline. See caption to Figure $3 a$ for description of symbols. (b) Histograms showing distribution of Imax, Iint, and Imin AMS directions in Hole 319A. See caption to

Figure $3 b$ for explanation. 